\title{
A stone axe-factory in Brittany
}

\author{
C.-T. LE ROUX
}

\begin{abstract}
Charles-Tanguy Le Roux in his capacity as Assistant de la Circonscription des Antiquités Préhistoriques de Bretagne (Service des Fouilles: Ministère des Affaires Culturelles), has carried out rescue digs of all kinds. He is at present preparing his doctoral thesis on the petrography of polished stone axes. The discovery of the stone axe-factory of Seledin in the commune of Plussulien (Côtes-du-Nord), the subject of this article, is the result of work done in this field; work that was begun by Professor P.-R. Giot and Professor F. Cogné in I949.
\end{abstract}

Following the way opened by several British archaeologists, Professors J. Cogné and P.-R. Giot undertook, just after the war, a systematic petrological study of Breton polished stone axes (Cogné and Giot, 1952, 1953, 1954, 1955, 1957; Giot, 1951, 1959, 1964). One of the illuminating results of this enquiry was to reveal that nearly 40 per cent of all the pieces examined were made of a single fine-grained and strongly epidioritized dolerite. This rock appeared remarkable by the very characteristic aspect of its leucoxene-coated ilmenite crystals, clustered together in short and randomlyoriented rows, a character which often allowed identification by the naked eye.

The rock was baptized 'Dolérite du Type $A$ ' and, although its outcrop remained unknown, was soon identified with the little 'Group VIIa' (now re-numbered as Group X) of the SubCommittee of the South-Western Group of Museums and Art Galleries (Evens, Grinsell, Piggott and Wallis, 1962; Cogné and Giot, 1953). This group counted, for the British Isles, three axes from Southern England, plus one from Jersey.

On the Continent, Type A axes are known in many parts of France, even as far from the Armorican massif as Somme, Aisne, Bas-Rhin and Haute-Garonne, to mention only the extreme finds. Typologically, the pieces are very diverse; out of the mass of 'normal' axes of varied types, the group contains nearly all the famous 'button-axes', characteristic of Western France, and even some perforated implements. Most of these objects are, of course, random finds, but a certain number come from varied archaeological surroundings, especially megalithic graves of diverse types (although they appear to be absent from the earliest passagegraves).

It was clear that a very important working place had to exist somewhere in the Armorican massif, on an outcrop of which the exact location remained unknown for many years. In the compass of a systematic prospecting of the Armorican greenstones suitable for axe-manufacturing, we examined, in 1965 , the important flows, of lower Carboniferous age, situated in the south-east of the Breton median syncline. They are generally very coarse-grained dolerites (and thus unsuitable for the purpose), but in a recent petrological study, MM. J. Nicolas and J.-P. Sagon described a few, closely-located, fine-grained outcrops which they considered to be the upper parts of the thickest flows (Nicolas and Sagon, 1963).

One of these outcrops, situated on the northern flank of the little Laniscat-Merléac anticline, not far from the village of Sélédin, yielded a rock identical with that of the Type A axes (FIG. I). The neighbouring fields, immediately prospected, produced an impressive mass of flakes of all sizes and a fair series of rough-outs closely comparable with those of 


\section{ANTIQUITY}

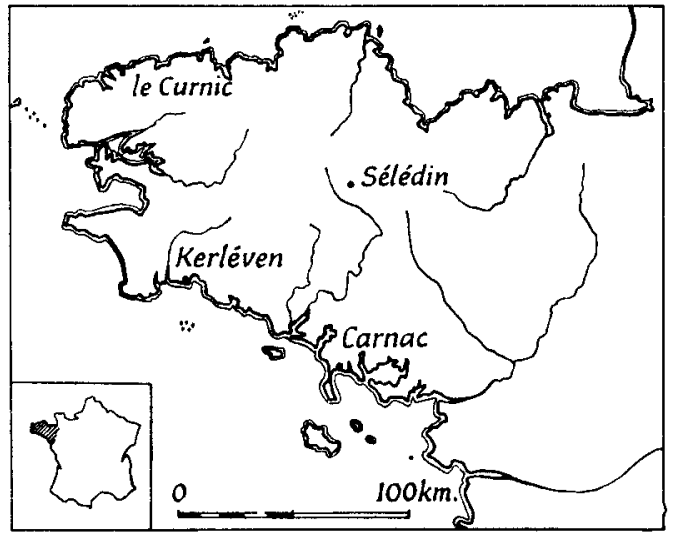

Fig. I. Map showing the main sites mentioned in the text

the well-known British and Irish stone-axe factories.

The fine-grained rock occurs on nearly $5^{\circ}$ hectares (125 acres) on the summit and the upper part of the north-west slope of a hill, constituted mainly of Devonian quartzite, which culminates at about $320 \mathrm{~m}$. above sea-level and dominates the Daoulas river, flowing in the Carboniferous schistose lowland. The working places cover not only the whole surface of the outcrop, but also the slope down to the river, extending over more than roo hectares (250 acres). It is almost certain that all this surface was not simultaneously in activity; nevertheless, this represents an impressive work, conducted on an industrial scale.

A site of this importance, free from any 'skimming' by collectors, was unhoped for in a country as anciently and completely cultivated as Brittany; we decided to plan methodically its scientific exploitation, and two preliminary campaigns, in 1966 and 1967 , took place in this way. They were voluntarily limited to surfaceprospecting and to a few very restricted trial trenches, but they permitted us to delimit precisely the extent of the factory, to spot the most promising places and, from the surface finds, to outline a preliminary typology (Le Roux, 1967; Giot, 1967, 1969).

In 1969 and 1970 , we undertook two campaigns of excavations, in the area of the main visible outcrop, nearly $\mathbf{I} \mathrm{km}$. east of Sélédin.
This one, locally called 'Roc' $h$-Pol', corresponds to the remains of a formerly much more important crag, dismantled by quarrying and half-submerged under a huge heap of flaking refuse.

The surface of the rock shows many signs of human activity, which can be summarized into four types:

I. 'Pock-marked' areas, more or less depressed and sometimes truly basin-shaped by intensive hammering; they seem to have been used as benches for trimming.

2. Protuberances covered by traces of severe hammering, which clearly correspond to anvil strikers used to break off large blocks.

3. Negatives of bulbs, sometimes huge ones, corresponding to blocks extracted by direct mace percussion.

4. Smoothed and hollowed surfaces, often associated with thin grooves; they lead one to believe that polishing was, at least sporadically, practised on the site.

It is not intended, in this preliminary article, to give a full description of the collected artifacts, but let us note briefly that direct evidence of these alleged activities has been found during the excavation, namely:

Hand-strikers of two types: large ones, weighing up to $5 \mathrm{~kg}$., probably managed with both hands, and smaller ones, of sub-sphaeroidal shape, for final trimming.

Grooved mace-heads, recalling those often described on many prehistoric industrial sites; weighing generally no more than I kg., they could make convenient tools when correctly hafted.

Anvils and benches still encrusted in a coat of crushed stone.

The excavation has been conducted simultaneously in four types of place: on the border of the mass of working residues surrounding the crag, on the surface of this accumulation, at the very foot of the rock and on the summit of the outcrop (FIG. 2).

The $\mathrm{O}_{4}$ area was opened rather low on the slope, in a part formerly cultivated but on a point protected by a 'modern' stone-heap. Nevertheless, nothing was found in position there and it was clear that the I m.-thick layer 


\section{A STONE AXE-FACTORY IN BRITTANY}

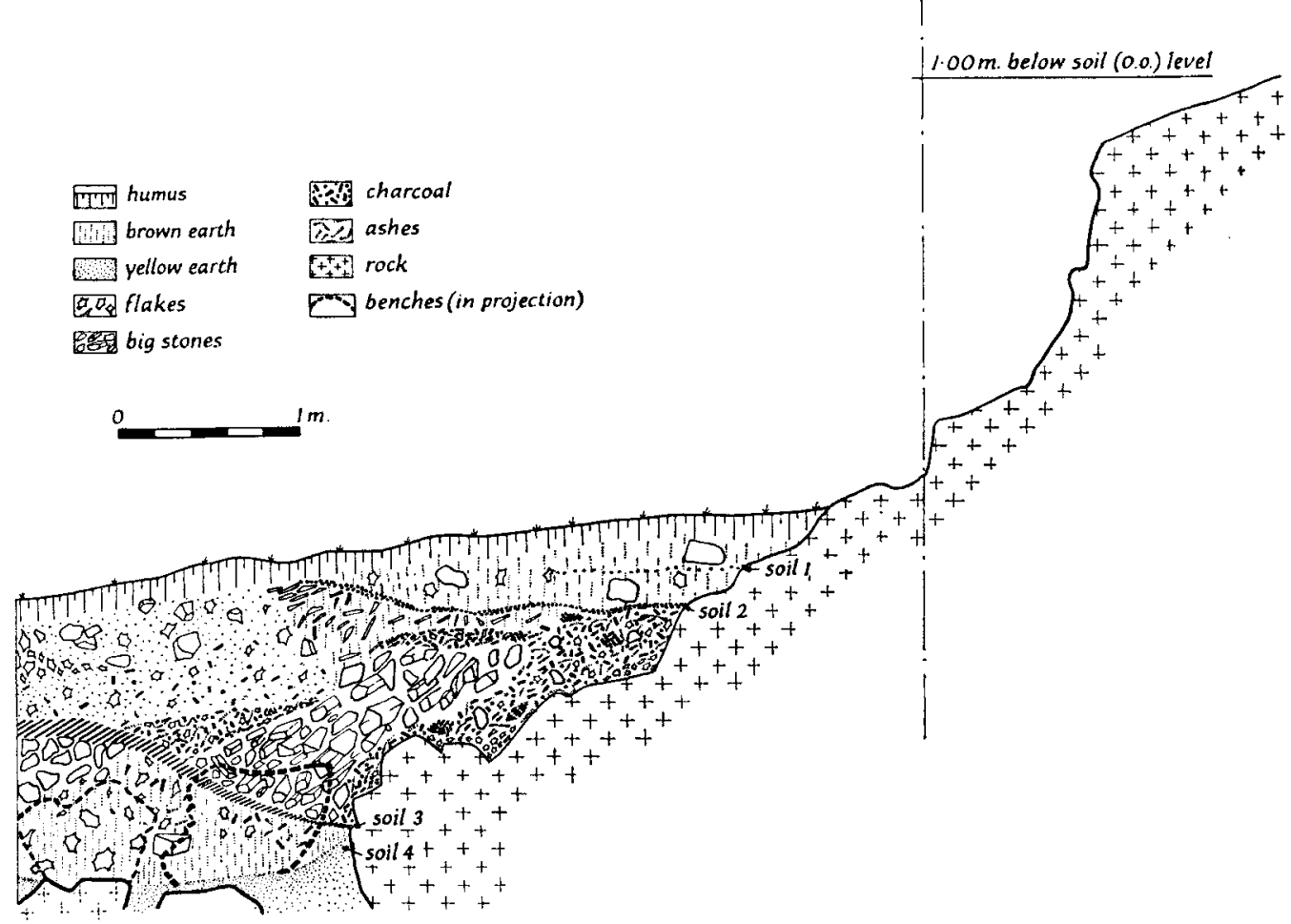

Fig. 2. The main section of the NI-Or excavation area

of clay and flakes encountered was the result of a general flow along the slope. A radiocarbon date, obtained from dispersed grains of charcoal, gave a date (GIF I 543: $4360 \pm$ I $30 \mathrm{BP}$ ) which, compared with the others obtained from the site, represents rather well an average figure, as we shall see.

The $\mathrm{N2}$ excavation was established some $20 \mathrm{~m}$. east of the crag, in a place where the flakes, retained by a secondary outcrop almost submerged by them, formed a plane surface. At a shallow depth $(0.30$ to $0.50 \mathrm{~m}$.) there was a light sub-horizontal discontinuity in the accumulation of flakes; the progressive cleaning of this surface revealed an old occupation level on which were encountered various structures: well-defined trails of nearly joined massive blocks separating clayish or ashy areas rich in small trimming flakes. Only one of these areas has yet been explored; it corresponded to a small pit, oval-shaped, of about $1 \mathrm{~m}$. long, $0.5 \mathrm{~m}$. wide and $0.2 \mathrm{~m}$. deep. It was crudely built of medium-sized blocks and filled up with tiny flakes embedded in ashy earth. A complementary excavation will of course be necessary in this area, but we presume that these structures represent the remains of a trimming post established at a fair distance of the quarrying place though still protected against dominant winds by the mass of the crag. This area has been dated from charcoal collected on an ashy zone of the old soil (GIF I $877: 5270 \pm$ I 40 BP).

The NI-OI excavation cleared the east foot of the main outcrop for a length of $8 \mathrm{~m}$. and revealed there a real quarry, filled by a nearly 2 m.-thick accumulation of blocks, flakes, rough-outs and charcoal, providing a complex stratigraphy of the utmost interest.

Under the modern turf (Soilo), the top of the section shows a mass of blocks, lately crumbled from the summit of the crag, including a local faint discontinuity (Soil $\mathrm{r}$ ). These blocks rest 


\section{ANTIQUITY}

on a thin layer of tiny flakes which corresponds to the summit of the stratified filling, and thus to the end of prehistoric industrial activity on the site (Soil 2).

Under this Soil 2, comes a thick intricate series, corresponding to Late Neolithic activity as shown by the radiocarbon date obtained from one of the uncovered hearths (GIF I $539: 405^{\circ}$ $\pm \mathrm{r} 30 \mathrm{BP})$ This series is characterized effectively by large hearths, occasionally established at some distance from the rock, but chiefly placed on a line, recognized over a length of more than $6 \mathrm{~m}$., at the very foot of the quarrying front. As shown by the aspect of the rock, these hearths appear to have been used for quarrying, in the technique still used not long ago by local farmers who wanted to clear out the rocks from their fields: heated strongly by a fire of faggots, the dolerite becomes brittle enough to be easily broken with a mace, which has been confirmed by our own experiments discussed below.

Underneath, a thick old soil (Soil 3) is associated with small hearths; two of them have been dated (GIF I540: $4700 \pm \mathrm{I}_{50}^{\circ} \mathrm{BP}$ and GIF $1872: 5100 \pm 140 \mathrm{BP})$, the latter being probably more accurate in view of its sampling conditions. It covered a second series of blocks and flakes which most likely corresponds to Middle Neolithic activity. There are no more large hearths, but we did uncover there a sort of large bench, made of two huge blocks, of several tons each, set side by side; their summits, nearly touching, form a large basin-shaped hammering place, quite similar to those visible on the top of the outcrop but still encrusted by cemented stone-dust. The bench is at a suitable level to provide comfortable working conditions for a man standing on the rocky sub-horizontal bottom of the quarry, which is coated by a thick layer of hardened clay ( Soil $_{4}$ ).

This Soil 4 may represent in part the old trampling surface, but also the accumulation of the earth percolated through the porous mass of flakes and trapped on this flat, damp and solid level. A radiocarbon date, obtained from charcoal scattered in the clay, effectively shows probable contamination by this silting, when compared with the date from the above-lying hearths of Soil 3 (GIF I 54I : 4500 \pm 130 BP), but a series of other samples, collected in better conditions from different points of the filling and from Soil 4 give well grouped results (GIF I873: $5^{1} 5^{\circ} \pm$ I 40 BP; GIF 1874:5075 \pm I40 BP; GIF 1875 : $4960 \pm 140$ BP; GIF 1876 : $5^{1} 5^{\circ} \pm 140 \mathrm{BP}$ ).

The foot of the bench is wedged in a pit, dug through the base of Soil 4 and attacking the rock underneath; it is not yet clear if this corresponds to an older quarrying place or not, but it is noticeable that this hollow is filled with an ashy dark earth, the summit of which has immediately yielded a fine small blade of translucent yellow flint, the first implement of this sort to be discovered on the whole site.

The Oo zone is situated on the top of the crag and on its western slope; here, a series of limited hollows has been cleared between the rocky stumps, which revealed traces of a modestscale activity, with quarrying by direct percussion, absence of important hearths and wide use of the anvil technique of flaking. Scattered grains of charcoal, collected at the bottom of an extraction hole and sealed by the mass of flakes gave a first date (GIF I542:4930 \pm I $30 \mathrm{BP}$, while a small hearth, well preserved in a hollow of the rock, confirmed this result (GIF I87I : $495^{\circ} \pm \mathrm{I} 4{ }^{\circ} \mathrm{BP}$ ). Moreover we discovered at the limit of the excavated area that the natural rock surface was coated with a faint layer of earth containing traces of charcoal which might correspond to the preliminary clearing of the site by fire; this of course needs confirmation.

The Sélédin factory, although still known incompletely, may already be compared with the well-known factories of Great Britain or Northern Ireland. Here and there, we deal with limited outcrops of peculiar rocks, favoured by their mechanical properties, which have been 'industrially' exploited and diffused, often over considerable distances. It is certainly not a matter of pure chance that the rocks in question so often belong to the 'greenstone' petrological group; these stones, with their intricate structure rich in more or less fibrous minerals, form a rather satisfactory compromise: brittle and fine-grained enough to flake correctly, they are, on the other hand, sufficiently hard and tough to provide tools of convenient solidity. 


\section{A STONE AXE-FACTORY IN BRITTANY}

Nevertheless, several individual features appear on the site of Sélédin: polishing is attested, though on a small scale, on the factory itself and, if no truly polished implements have been found on it, we do have several examples of preliminary picking and at a distance of less than a kilometre there is a dwelling place relatively rich in stone axes.

Concerning quarrying with the aid of fire, as testified in the Late Neolithic layers, we have conducted some experiments in an electric faience kiln to obtain known temperatures and heating rates. At high temperature, the dolerite becomes actually very brittle and a large block is easily broken with a hammer, without formation of a conchoïd, which explains the massive and angular shape of the crude blocks found on the site. Experiment also shows that a slow cooling rate restores the normal flaking properties of the rock. For instance, a block of about ro kg. was heated to a surface temperature of approximately $400^{\circ} \mathrm{C}$. in $\mathrm{I} \frac{1}{2}$ hours and returned to ambient temperature by air cooling in 3 hours without significant alteration of its properties. On the contrary, to accelerate the heating (i.e. up to $400^{\circ} \mathrm{C}$. in $\frac{1}{2}$ hour) or, even more, cause brutal cooling by water sprinkling, appears to produce cracks which render impossible any correct flaking. The quarrying technique used on the site appears very well adapted to the local conditions and the hearths uncovered represent a particularity of the Sélédin factory, quite different, for instance, from the secondary hearths described at Mynydd Rhiw in the quarry of Site B, which appeared unconcerned with the factory itself (Houlder, I96I).

Another original character of the Selédin factory is its vicinity to a fair number of dwelling places, menhirs and megalithic tombs some of them less than $\mathrm{I} \mathrm{km}$. from the excavation. Their abundance some ten $\mathbf{k m}$. around is quite unusual for central Brittany and seems directly linked to the factory, at least in the Late Neolithic. All the megalithic graves of the area are in effect rather late, Gallery-graves and more or less related types as V-shaped or Lateral entrance graves. On the contrary, for older periods, the whole region curiously appears as an archaeological blank whereas we know from radiocarbon dates that the factory was already in activity well before $3000 \mathrm{BC}$. The nearest important neolithicized region appears to have been then the coastal Morbihan, some $5 \circ \mathrm{km}$. to the south. Communications between the two areas, by the Blavet or Oust and lower Vilaine valleys, were not very difficult and actual links are attested by the abundance of Type A dolerite fragments on the islet of Er-Lannic and in the Camp-du-Lizo at Carnac.

The stratigraphy uncovered in the quarry of the $N \mathrm{I}-\mathrm{O}_{\mathrm{I}}$ area is divided chiefly into two parts by Soil 3, which is nearly as well marked as the modern turf and thus clearly marks a prolonged halt in the activity. This halt may be of course quite local and correspond to the parallel opening of another quarry; nevertheless, clear differences appear between the upper levels (large quarrying hearths and hand-strikers only) and the lower ones (lack of hearths but quarrying by percussion and presence of anvils and benches). The former are well dated to the Late Neolithic (c. 2100 BC) while the latter appear to be clearly older than $3000 \mathrm{BC}$. This date fits well with the technical similarities which can be noted with the $O 0$ area and the $\mathrm{N} 2$ working place. In the excavated sector, the Late Neolithic levels appear as an important re-opening of a pre-existing but abandoned quarry with its own important industrial remains. Nevertheless, the wide diffusion of Type A axes in Late Neolithic times leads one to suppose that the recent phases of exploitation should be dominant on other parts of the outcrop.

Two successive aspects of the site emerge from these considerations: first, an 'ancient' period in which the factory probably appeared as a 'distant mine' for the Neolithic cultures which flourished on the Morbihan shore but were rather reluctant to turn away from the coastal area and settle further in the north than the first hill-line of the 'Landes de Lanvaux'. This situation leads one to invoke problems of cultural relations more or less of the same type as those recently discussed for the Dunmury and Larnian cultures in Northern Ireland (Case, r969). Afterwards, a second phase took place with quarrying conducted on new and original 


\section{ANTIQUITY}

technical bases, linked with a local important human concentration. This 'industry' probably then became a major element of prosperity for these Late Neolithic peoples who settled widely in central Brittany but appear to have almost crowded in the vicinity of the factory.

We do not intend to develop here the problem of the diffusion of the Type A axes, but let us evoke it in a few words. As we have seen, the oldest Breton Passage-graves which are now well dated from the fourth (or even the end of the $5^{\text {th }}$ millennium $\mathrm{BC}$ if we correct the radiocarbon dates in terms of absolute chronology), seem to represent a 'pre-Type $A$ ' period. On the other hand, as it appears that the Sélédin axes were still in use at the very end of the
Neolithic, the major problem is to date the beginning of their diffusion, especially in Brittany. Two sites from Finistère which have, among many others, yielded Type $A$ axes are peculiarly interesting from this point of view: the dwelling site of Le Curnic en Guisseny with its series of dates from $515^{\circ} \pm 150$ to $4525 \pm$ I40 BP (Giot, L'Helgouach and Briard, I966) and the megalithic cairn of Kerleven en La Forêt-Fouesnant, dated $4825 \pm 125$ BP (Le Roux and L'Helgouach, 1967). On both sites, typical Chassey pots, including 'Vasesupports', were also found, which help us to place this Middle Neolithic diffusion in the regional archaeological chronology.

\section{BIBLIOGRAPHY}

CASE, H. r960. Settlement patterns in the North Irish Neolithic, Ulster Fourn. of Archaeology, xxxI, 3-27.

COGNE, J. and P.-R. GIOT, 1952. Etude pétrographique des haches polies de Bretagne, I, Bull. Soc. Préhist. Française, xuIx, 388-95.

1953. ibid., II, $B S P F$, L, 37-9.

I954, ibid., III, BSPF, LI, 28.

1955. ibid., IV, $B S P F$, LII, $401-409$.

1957. ibid., vi, $B S P F$, LIV, 240-4I.

EVENS, E. D., L. V. GRINSELl, S. PIGGOTT, and F. S. wallis. I 962. Fourth report of the Sub-Committee of the South-Western group of Museums and Art Galleries on the petrological identification of stone axes. Proc. Prehist. Soc., xxviII, 209-66.

GIOT, P.-R. 195I. A petrological investigation on Breton stone axes, Proc. Prehist. Soc., XVII, 228.

1959. Etude pétrographie des haches polies de Bretagne, vi, Bull. Soc. Préhist. Française, Lvi, 43-5.

1964. Résultats de l'identification pétrographique des matériaux des haches polies en France septentrionale, Studien aus Alteuropa, I, 123-33. 1967. Informations, Gallia-Préhistoire, x, 334-5. 1969. Informations, Gallia Préhistoire, XII, 440.
GIOT, P.-R., J. L'HELGOUACH, and J. BRIARD. I965 Le site du Curnic en Guissény (Finistère), Annales de Bretagne, LxxII, 49-70.

HOULDER, C. H. 196r. The excavation of a Neolithic stone implement factory on Mynydd Rhiw in Caernarvonshire, Proc. Prehist. Soc., xxvIr, I08-43.

LE ROUX, C.-T. I967. In, P.-R. GIOT, Chronique de préhistoire et de protohistoire pour les Côtes-duNord, Bull. Soc. Emulation des C.-du-N., xCV, 8-9.

1970. ibid., XCViII, 5-8.

LE ROUX, C.-T. and P.-R. GIOT, r965. Etude pétrographie des haches polies de Bretagne, vII, Bull. Soc. Préhist. Franfaise, CRSM, LXII, cxxviiixxix.

LE ROUX, C.-T. and J. L'HELGOUACH. 1967. Le cairn mégalithique avec sépultures à chambres compartimentées de Kerleven, commune de la Forêt-Fouesnant(Finistère). Annales de Bretagne, LXXIV, 7-52.

NICOLAS, J. and J.-P. SAGON. I963. Nouvelles observations sur les roches vertes de l'anticlinal de Laniscat-Merléac (Côtes-du-Nord), Bull. Soc. Géol. Français (7), v, 844-5 I. 